\title{
Geografia: o olhar e a imagem pictórica
}

Cláudio Benito Oliveira Ferraz*

Resumo: Este artigo objetiva apresentar, de forma introdutória, a possibilidade e a necessidade de diálogo entre a linguagem pictórica e o discurso científico da Geografia. Para tal, apresenta alguns elementos do alfabeto das pinturas de imagens a partir tanto da semiótica quanto da gestalt, analisadas por Fayga Ostrower e Donis Dondis. O exercício interpretativo dá-se a partir do conceito de paisagem aplicado sobre as imagens elaboradas artisticamente por grandes pintores da humanidade, contextualizando-as a partir dos elementos técnicos e tecnológicos que existiam na época e no lugar, e da forma como esses interferem nos processos de elaboração e interpretação das obras. Para exemplificar isso, utilizam-se três pinturas elaboradas em diferentes períodos, a partir da Europa medieval até o mundo moderno, apresentando, assim, os aspectos gerais que levavam à mudança de leitura espacial do território produzido a partir da consolidação do mundo urbano, industrial e baseado na lógica da mercadoria.

Palavras-chave: Geografia; pintura; linguagem; imagem; paisagem.

\section{Geography: the viewpoint and the pictorial image}

Abstract: This article is aimed at presenting some introductory remarks on the possibility and the need for dialogue between the pictorial language and the scientific speech in geography. For such, it presents some elements used in the painting of images based on both semiotics and the Gestalt theory, analyzed by Fayga Ostrower and Donis Dondis. The interpretative exercise happens thanks to the landscape concept applied to the images created artistically by great painters from history. This exercise contextualizes these images considering both the technical and technological elements which existed at the time and place where they were produced and how these elements interfered in the processes of creating and interpreting theses masterpieces. To illustrate this, we have used four paintings from different periods, from the medieval Europe time to the modern world, hence introducing the general aspects which led to a change in the spatial reading of the territory produced after the consolidation of an urban, industrial world based in a merchandizing logic.

Key words: geography; painting; language; image; landscape.

* Geógrafo, professor do Departamento de Educação e Coordenador do Grupo de Pesquisa Linguagens Geográficas (GPLG) da Faculdade de Ciências e Tecnologia da Universidade Estadual Paulista (FCT/Unesp) de Presidente Prudente, SP, e do Programa de Pós-Graduação em Geografia da Universidade Federal da Grande Dourados (UFGD), MS, Brasil. cbenito2@yahoo.com.br 
A experiência vivida e revivida no significado

Não é a experiência de uma vida apenas Mas a de muitas gerações - não esquecendo algo que, provavelmente, será de todo inefóvel:

O olhar para além da certeza

(T. S. Eliot, The dry salvages)

\section{Introdução}

Olhar certa paisagem e representá-la pictoricamente é uma tradição que acompanha o homem desde os primeiros passos de sua evolução racional, emocional e civilizatória, ou seja, um ser que pensa/sente o mundo, tenta comunicar suas impressōes para um ser outro por meio de palavras (escritas ou orais) e imagens (desenhadas, gestuais, pintadas e expressōes diversas), de forma a gerar sentido de compreensão, identificação, incômodo e interpretação-recriação das representaçôes por ele elaboradas.

Ao que nos aqui interessa, aprimorar a leitura geográfica do mundo, vamos tentar focar esse processo de comunicação e entendimento do mundo através do uso das imagens e entender como, dentre os vários mecanismos elaborados para abordá-las, podemos instrumentalizar-nos por meio de análises estéticas e sígnicas na direção de uma interpretação espacial das relações humanas a partir de suas representaçôes pictóricas. Não se vai aqui verticalizar num estudo conceitual e de caráter semiótico da questão, mas optar por uma postura mais didática de emprego desses referenciais na abordagem de obras que exemplifiquem essa prática possível e necessária à Geografia.

Segundo Ostrower (1988), o que exprime a excelência da humanidade do homem é sua capacidade de compreender e (re)criar o mundo e a si próprio, e esta singularidade da espécie desemboca nas "qualidades estéticas: ao senso de harmonia e de beleza que os homens são capazes de entender nas ordenações universais."(p. 181). Essa capacidade de entender as complexas relaçôes presentes no real a partir do olhar ${ }^{1}$ permite ao homem interpretar e expressar esse entendimento "visualmente pelas imagens de arte".

Para o geógrafo ${ }^{2}$, que tem no olhar a paisagem o ponto de partida do processo de estudo e reflexão sobre os determinantes espaciais da sociedade, assim criando subsídios para o ser humano mais bem localizar-se e orientar-se no

1. O sentido do olhar, para a autora, é o proposto por Cumming (1996, p. 13), qual seja, o de não se reduzir ao visualizar em si, mas o olhar com a "mente aberta e usando do intelecto".

2. Esclareço aqui que, ao longo do texto, o termo "geógrafo" será empregado em um sentido mais amplo, englobando o pesquisador e o professor de geografia, ou seja, o profissional que exercita o domínio da linguagem geográfica. 
mundo, o aprimorar esse olhar a partir da experiência acumulada pelos artistas em seus quadros e obras pictóricas torna-se de grande importância e de crucial necessidade para a sua formação.

Olhar a paisagem e não fazer dela apenas uma descrição empobrecedora e circunscrita a alguns elementos estáticos e desconectados significa tentar interpretar, vendo, com maior riqueza, a dinâmica da paisagem, e perceber a dialética relação de aparência/essência que carrega em seu interior o expressar/ocultar os elementos e os processos que determinam a realidade sócio-espacial do mundo ou, como aponta a epígrafe, "olhar para além das certezas". Esse olhar significa ampliar o sentido de paisagem à geografia, para ir além e aquém do entendimento usual que se tem dela, identificando as sombras e os processos não aparentes que se imbricam naquilo que se mostra como vidente/evidente ${ }^{3}$. Eis o que o geógrafo tem como tarefa.

Exercitar a leitura das "qualidades estéticas" do olhar geográfico sobre a paisagem a partir da análise das pinturas é um caminho possível e altamente enriquecedor para o processo de discussão entre as ordenaçôes espaciais da sociedade, do cotidiano e do mundo como um todo, em suas diversas expressões paisagísticas. Estabelecer parâmetros mais amplos e fundamentados dessa relação paisagem/espaço sempre foi uma constante na obra dos grandes pintores; por que, então, os geógrafos deveriam deixar de pensar essa relação também por essa perspectiva?

Fayga Ostrower (1988) contribui, nesta discussão, demonstrando o aspecto crucial da linguagem pictórica expressa nos quadros dos grandes mestres como possibilidade de entendimento acessível a todos - apesar da diferenciação de estilos, gostos e épocas entre o elaborar e o apreciar um quadro. Neste ponto, ela questiona: "Que linguagem é esta?", ao que responde:

De fato estamos na presença de uma metalinguagem, que serve de referencial a todos os modos de comunicação humana: é a linguagem de formas de espaço (p. 172).

Mas o que vem a ser esta "linguagem de formas de espaço"?

[...] é a expressão direta de vivências existenciais que todos nós fazemos de modo semelhante, todos os seres humanos [...] Cada pessoa passa pelas mesmas experiências do espaço, para poder crescer, tornar-se consciente e conquistar sua identidade (p.172).

3. "A paisagem é dialética. Nada melhor que o espaço para nos dar conta disto [...] $\bigcirc$ que a paisagem não nos revela é o conteúdo das contradições que nos põe sensorialmente à frente. Este conteúdo quem nos revela é a essência, e a paisagem é a aparência." (Moreira, 1987, p. $|8|)$. 
E mais à frente complementa:

[...] pois as formas de espaço constituem tanto o meio como o modo de nossa compreensão. Formando as imagens para nossa imaginação, o espaço se torna o mediador entre a experiência e a expressão. Só podemos pensar e imaginar mediante imagens de espaço (p.173).

A partir da observação de Ostrower sobre a pertinência da linguagem das formas de espaço como meio para que os indivíduos dialoguem suas experiências vivenciais através das imagens que as referenciam, vislumbra-se o sentido dessa espacialidade, passível de ser apreendido pelas imagens elaboradas pelos artistas pintores. É possível identificar, a partir do que a autora afirma, a importância das "formas de espaço" (tomado aqui em sua expressão paisagística) na caracterização do homem e da sociedade. As "formas" e as "imagens de espaço" contribuem para que os indivíduos, em suas relações sociais, estabeleçam sentidos de orientação e localização; portanto, de entendimento da vida humana no mundo.

A partir da representação paisagística expressa em quadros, pode-se colher e identificar aquilo que se encontra além das imagens em si, fazendo da paisagem representada uma força propulsora de sentidos diversos. Faz-se isso a partir das experiências pessoais produzidas e vivenciadas espacialmente; logo, o espaço é o elemento que permite decifrar/interpretar a linguagem pictórica ${ }^{4}$. A linguagem espacial é tomada como referência básica, pois por meio dela é que se produzem os sentidos interpretadores de nossa existência ${ }^{5}$.

Portanto, ao ver a paisagem, não se está propriamente vendo a realidade em seu todo espacial e concreto, pois a "realidade que os olhos mostram é uma sombra extremamente pobre da realidade" (Tápies, 1995, p. 7), mas o olhar com os "olhos da mente" pressupõe ir além dessa sombra, buscando os elementos que a provocam. Parte-se da imagem e busca-se o sentido paisagístico que expressa o perceptível de determinado aspecto do mundo. É isto que a representação pictórica tenta apresentar, e é este olhar, este exercício estético de

4. Mas não só a pictórica, pois o espaço vivido é a linguagem de experiências acumuladas no tempo, na qual se baseiam todas as demais linguagens. "[...] o espaço será o referencial ulterior de todas as linguagens." (Ostrower, 1988, p. 173).

5. "O espaço geográfico ocupa assim, via seu arranjo territorial, um papel tão importante nos esquemas de gestão de sociedade, que ninguém pode ficar indiferente." (Moreira, 1987, p. I 82). Dessa forma, o espaço permeia a organização da sociedade como um todo, refletindo no cotidiano e na vida de cada indivíduo, de maneira que, na singularidade de cada existência, ocorram fatores comuns que levem à interação, ao diálogo e a trocas de experiências. Entendemos aí o sentido de "espaço vivenciado". 
observador/criador, que interessa ao geógrafo, ao professor e ao aprendiz de Geografia.

\section{O texto das obras - as bases da linguagem pictórica}

Para elaborar sua obra pictórica, o artista utiliza um alfabeto básico que, conforme sua maestria, emprega de forma variada. Esse alfabeto pressupõe o desenvolvimento de um estilo a partir do emprego da cor, da luz e de materiais específicos, os quais deverão ser combinados segundo os "limites de percepção" do pintor ${ }^{6}$.

Voltamos aqui à questão dos limites do homem perante a compreensão do mundo, já apontado por Eliot (1981) em nossa epígrafe. A obra de arte expressa esses limites, que são deslocados no ato de sua reinterpretação; esse deslocamento ocorre quando outros apreciadores, em outros locais e momentos, observam a mesma obra. Para o artista que a elaborou, ela é fruto de seu tempo/ espaço específico, tendo ele - ou não - consciência disso, ou seja, de como utilizou determinados recursos para dar forma a uma dada representação segundo os padrões tecnológicos disponíveis e os referenciais estéticos possíveis de serem reafirmados ou questionados: esses sãos os "limites perceptivos".

Para compor esses limites perceptivos, o pintor organiza a distribuição de imagens numa determinada ordenação de movimentos e segundo certa estrutura de pesos e importâncias de temas a serem trabalhados a partir do motivo principal (Ostrower, 1988).

A título de exemplificação, podemos afirmar, de forma bem sintética, que o pintor faz uso de linhas retas, verticais e horizontais, para expressar a idéia de estabilidade e tranqüilidade ou ausência de movimento; já o emprego de curvas, diagonais e linhas inclinadas leva à idéia de movimentação e deslocamento, passando o sentido de tensão e/ou desequilíbrio na cena pintada.

Geralmente, um quadro é pintado sobre um plano bidimensional que possui um ponto central, um centro geométrico que determina o equilíbrio mecânico - físico - do quadro. Ao distribuir imagens, cores, luzes, retas e curvas ao longo do quadro, o artista cria um centro perceptivo que varia conforme a leitura que o apreciador faz do quadro, o que determina um equilíbrio dinâmico. O "centro geométrico" é fácil de detectar, mas o "perceptivo" é fruto do

6. O conceito de "limites perceptivos" pode ser entendido como os fatores sociais e culturais complexos e contraditórios - que permitem aos membros de uma sociedade, em tempo e local próprios, dialogar, criar e ler representações possíveis de entendimento, mesmo que a partir de elementos não semelhantes entre si. Para tal, o nível tecnológico, das técnicas e das linguagens empregadas é fundamental para os processos de criação e interpretações das obras. 
contexto temático do quadro na relação com o momento em que se coloca o observador e com os objetivos deste ao observar.

A percepção humana tende a relacionar maior peso visual às partes inferiores dos objetos e figuras, daí que, na ordenação de movimento, os pintores tendem a distribuí-los em diagonais que se deslocam de cima para baixo e da esquerda para a direita, como usualmente idealizamos a nossa percepção de deslocamento dos objetos no espaço.

O uso desses referenciais de organização-ordenação-estrutura não significa uma camisa-de-força; longe disso, estão arrolados aqui apenas para exemplificar que ninguém pinta a esmo, mas a partir de determinados parâmetros, fazendo uso de um alfabeto próprio que precisa dominar para poder radicalizá-lo e/ou subvertê-lo. É importante ter essas noções para melhor compreender como o homem foi dando forma pictórica aos limites de sua percepção ao longo de seu evoluir, o que genericamente significa a capacidade do homem para expressar a linguagem espacial vivenciada e percebida via representações paisagísticas elaboradas por meio da sua tradução em linguagem pictórica.

Para não ficarmos muito presos aos elementos inerentes à linguagem pictórica, pois nosso objetivo é mais perceber como esta permite ler determinado arranjo espacial, vamos aqui fazer uso de Donis Dondis (1997, p. 23) como forma de resumidamente colocar os principais elementos desta linguagem.

O ponto, a unidade visual mínima, o indicador e marcador de espaço; a linha, o articulador fluido e incansável da forma, seja na soltura vacilante do esboço seja na rigidez de um projeto técnico; a forma, as formas básicas, o círculo, o quadrado, o triângulo e todas as suas infinitas variações, combinações, permutações de planos e dimensões; a direção, o impulso de movimento que incorpora e reflete o caráter das formas básicas, circulares, diagonais, perpendiculares; o tom, a presença ou ausência de luz, através da qual enxergamos; a cor, a contraparte do tom com o acréscimo do componente cromático, o elemento visual mais expressivo e emocional; a textura, óptica ou tátil, o caráter de superfície dos materiais visuais; a escala ou proporção, a medida e o tamanho relativos; a dimensão ou movimento, ambos implícitos e expressos com a mesma freqüência.

Esses elementos visuais são utilizados conforme a técnica empregada pelo artista, técnica esta que pode visar o contraste, por meio da criação de sentido de "instabilidade", "irregularidade", "complexidade", "exagero", "distorção", etc. ou visar a harmonia, por meio do "equilíbrio", "simetria", "regularidade", "sutileza", "estabilidade", etc. Tanto a harmonia quanto o contraste podem ser empregados na elaboração de uma mesma obra, através dos diversos elementos 
já citados, notadamente através das formas, do emprego das cores e do tom, os quais darão os sentidos de luminosidade e de sombras necessários.

É claro que, para melhor entendimento e apreciação dos quadros, conhecer os contextos espacial e temporal em que foram elaborados e a história que cada um quer representar muito auxilia para melhor analisar a aplicação dos elementos da linguagem pictórica na interpretação das obras. Essa base de leitura é que enriquece o sentido espacial que podemos elaborar a partir das formas, das maneiras e dos contextos em que as imagens foram trabalhadas pelo artista.

\section{O contexto das obras — o espaço e as tecnologias de criação e as de interpretação}

Cada artista elabora sua obra a partir do contexto tempo-espacial em que se encontra. $\mathrm{O}$ uso de determinados recursos técnicos (tintas, corantes, papel, etc.) e tecnológicos (desenvolvimento da perspectiva espacial, por exemplo, ou da digitalização de imagens, etc.), em acordo com os valores éticos e estéticos hegemônicos de seu meio social, afeta o processo de criação, tanto no sentido de atendimento ao gosto hegemônico quanto no sentido de romper com as normas e os padrões convencionais. Por exemplo, o puritanismo do renascimento holandês ou a liberalidade sexual da Belle Époque francesa delimitaram formas diferenciadas de elaboração e apreciação do que era considerado belo e correto ou feio e errado no registro pictográfico.

$\mathrm{O}$ mesmo ocorre com a condição tempo-espacial em que o apreciador da obra se encontra. $\mathrm{O}$ que foi considerado horroroso e não artístico quando das primeiras telas impressionistas hoje é entendido como genialidade e arte de rara beleza estética. Ou seja, uma obra de arte passa por constantes processos de recriação de significados, a partir da relação contextual entre o seu momento de elaboração e seu momento de interpretação. É essa relação contextual do ver-interpretar-expressar que permite hoje melhor entender os limites e o transformar perceptivos, ou seja, as formas específicas de leituras do tempo-espaço do mundo.

A esse respeito, Cumming (1996, p. 7) afirma que os artistas, ao elaborar suas obras, "deviam presumir que seu público estava familiarizado com essas histórias" presentes em seus quadros, o que normalmente não ocorre ao apreciar uma pintura elaborada em outro período, porque se vivem outros limites perceptivos do saber humano. No entanto, podem-se redescobrir alguns dos significados presentes em obras passadas a partir do "estudo dos quadros e crenças da sociedade que formou o artista”; em outras palavras, há que instrumentalizar o olhar para ler um quadro como se lê a paisagem. 
Visando reforçar essa relação entre o contexto espacial e as imagens pictóricas, exemplifiquemos com uma pintura que expressa a paisagem de um período tempo-espacial que a humanidade, notadamente em sua linhagem euroocidental, produziu. Vamos ater-nos ao período de fins da Idade Média, por ser este muito rico no processo de evolução dos limites perceptivos, o que trouxe, não de forma retilínea e mecânica, grandes influências para as discussões que até hoje permeiam as artes e a sociedade moderna no que tange às diversas relaçôes: razão-sensibilidade; ciência-arte; cotidiano-história; Estadosociedade; natureza-homem; democracia-capitalismo, etc.

Basicamente, a pintura na Idade Média européia é caracterizada por representações de temas bíblicos em imagens achatadas e sem expressão emocional, pois expressar emoção era atributo do homem pecador. Não havia perspectiva e profundidade nas imagens, e o tamanho das figuras que as compunham geralmente nos tetos dos templos e vitrais - espelhava a hierarquia míticoreligiosa, ou seja, quanto maior a figura, maior sua importância bíblica. A distribuição destas também seguia o peso hierárquico, segundo o qual os mais importantes localizavam-se no alto, estando os demais olhando para cima em sinal de devoção e respeito.

Podemos exemplificar essa forma de representação pictórica com a imagem "Cristo e os 24 anciãos" (Figura 1), encontrada no livro do "Apocalipse de beatos", elaborada no início do século XI. Reflete esta obra toda a cosmologia medieval, a forte hierarquia social espelhada numa espacialidade em que o mundo terreno se imbrica com o mágico-teológico. $\mathrm{O}$ volume e o tamanho da imagem de Cristo, no alto e no meio da pintura, para o qual convergem todos os olhares e adorações, é uma representação clássica do período.

Para melhor compreender o sentido ético e estético com que se entendia a espacialidade da época, vamos usar aqui as idéias de Tomás de Aquino. Este cristianizou o pensamento aristotélico, o qual elaborara uma física cósmica a partir da divisão do universo em esferas sobrepostas. Aquino adequou esses parâmetros ao espaço medieval, em que a parte superior do cosmos terrestre, ou o mundo supralunar, era o local dos movimentos perfeitos. Estes dominavam os movimentos imperfeitos do mundo sublunar (a Terra), estabelecendo uma hierarquia de físicas distintas, de controle e determinação, aplicando essa hierarquia de forças aos seres biológicos do mundo sublunar, onde cada ser ocupa um lugar específico na ordem natural das coisas. Assim, a metafísica hierarquizada e naturalizada de Aristóteles explica a física, a biologia e a organização espacial da Terra. 


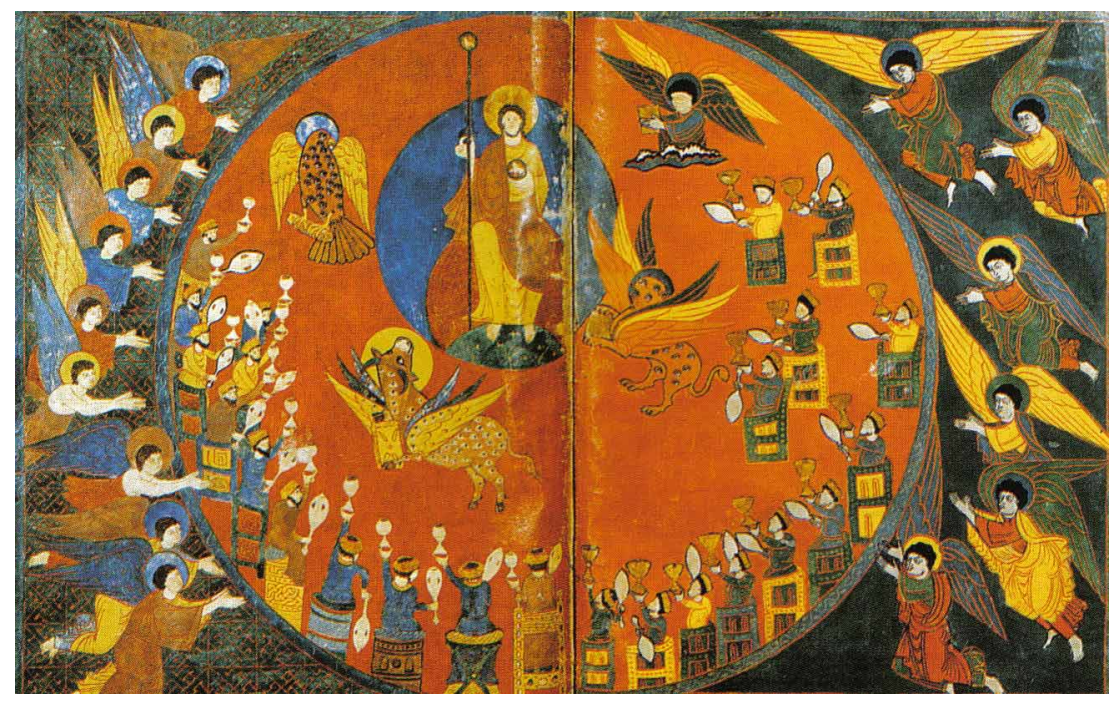

Figura I. Cristo e os 24 anciãos, Apocalipse de beatos (Autor desconhecido), 1024. Biblioteca Nacional de Paris.

Fonte: Wendy Beckett. História da pintura, p. 32.

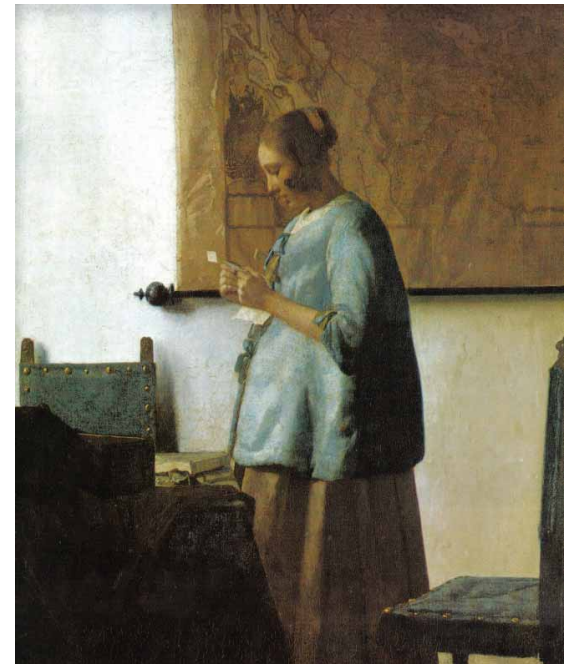

Figura 2. Mulher de azul lendo uma carta (J. Vermeer), 1664. Rijksmuseum, Amesterdan. Fonte: <pt.wikipedia.org/wiki/ Johannes_Vermeer $>$.

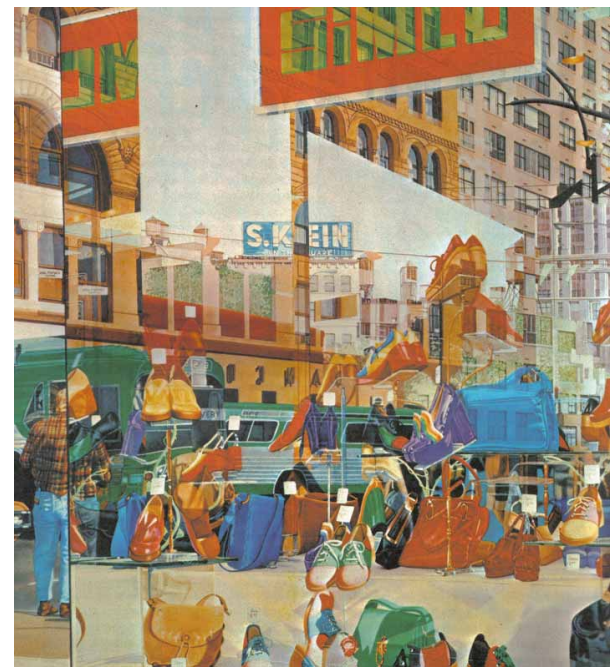

Figura 3. Sapatos novos para H. (Don Eddy), 1974. Museu de Arte de Cleveland. Fonte: <www.artregisterpress.com>

Adaptando essa concepção aristotélica do cosmos a uma sociedade altamente hierarquizada, como era a sociedade feudal, Tomás de Aquino acabou por fundamentar os limites perceptivos que o homem possuía na época em relação 
ao seu espaço vivido. Como Deus era o grande motor e a origem do movimento supralunar a condicionar todas as relações do ambiente sublunar, restava ao homem, ser imperfeito e inferior, obedecer à ordem natural e eterna das coisas que desconhecia, não questionando essa "verdade revelada" (Deus e sua perfeição representada pela Igreja), pois o imperfeito não pode duvidar ou entender o que lhe é superior, o perfeito - deve apenas crer nessa verdade como forma de conseguir o perdão divino pelos seus erros mundanos.

Mas, quando Tomás de Aquino sistematizou esse seu pensamento, os perigos iminentes advindos com a crise da teologia medieval já se pronunciavam fortemente no horizonte. $\mathrm{O}$ contato com o mundo muçulmano e a reintrodução de livros escritos pelos gregos cerca de mil anos antes, que questionavam verdades caras ao imaginário teológico medieval, assim como o crescimento econômico e político de certas cidades e classes sociais, desafiaram o monopólio da Igreja e dos grandes senhores de terra, apontando para o surgimento de novas necessidades sociais.

Com a crise da sociedade feudal, pôde-se melhor detectar o choque de percepçóes entre o espaço de uma sociedade fundamentada na aristocracia rural — fortemente influenciada pela teologia institucionalizada pela Igreja - e uma nova espacialidade, fruto dos valores e das estruturas urbano-burguesas, na qual a economia - pautada nas trocas comerciais e na transformação industrial de matérias-primas em produtos de consumo - cobrava novas tecnologias de comunicação, transporte e produção, além de mecanismos mais eficientes de controle territorial.

Com a Renascença, iniciou-se um processo de resgate do homem como ser privilegiado da criação, passando de observador passivo a intérprete da lógica da criação, chegando, ao final desse processo de mudança de lugar na ordem da criação, a assumir-se como produtor e controlador das próprias forças da natureza. Esta deixou de ser encarada como fonte dos pecados e do desconhecido, passando a ser elemento de inspiração e de investigação por meio da razão humana. Assim, a "verdade revelada" ao homem transmutou-se na busca humana pelo sentido verdadeiro das coisas através do emprego da razão.

O desenrolar dessa tendência à valorização do homem no imaginário europeu iria desembocar no pleno desenvolvimento da espacialidade moderna, com sua lógica urbana, consumista, pautada em sistemas cada vez mais rápidos e amplos de comunicação e circulação, seja de produtos, seja de informações. Um mundo em que a fragmentação e o poder espetacularizante da imagem passariam (ou "passaram") a determinar os padrōes perceptivos e estéticos.

Esse novo padrão de organização espacial da sociedade gerou desde ideais por um mundo melhor e mais justo, a partir da opulência advinda com o emprego racional da ciência, até reaçóes e críticas às injustiças das desigualda- 
des sociais e econômicas, assim como à perda da identidade do homem como ser natural, à alienação provocada pela exploração do trabalho e pela loucura e artificialidade da vida urbana.

Esse conflito entre o que e como olhar a sociedade capitalista (urbana e industrial) é o que identificamos ao antepor quadros como Mulher de azul lendo uma carta (Figura 2) e Sapatos novos para $H$ (Figura 3). O primeiro foi terminado em 1664 pelo holandês Johannes Vermeer (1632-75), na época em que a Holanda era uma das nações mais poderosas do mundo, e registra o ideal burguês de lar: limpo, calmo, feliz, organizado e expressando poder e riqueza (como se constata no mapa do Estado Holandês ao fundo), bem como a crença num futuro de fausto e progresso, personificado na gravidez da mulher.

O uso de cores claras, como o azul e o pastel, assim como o emprego da luz e das sombras, passa o sentido de tranqüilidade que fica reforçada pela correta distribuição dos objetos na cena e pelo uso de linhas verticais e horizontais e formas quadrangulares, delimitando a idéia de harmonia entre o mundo (o mapa) e a vida privada (a sala em que se encontra a mulher).

A obra seguinte, Sapatos novos para $H$. (Figura 3), foi pintada pelo norteamericano Don Eddy e complementa de forma conflituosa as imagens presentes na Mulher de azul lendo uma carta. A pintura é de 1974 e focaliza, através dos recursos de contrastes, sobreposição de imagens e cores, a loucura urbana, apresentando imagens fracionadas, profusão de objetos e movimento alucinado, em imagens translúcidas e atordoantes.

O quadro de Eddy abusa de cores fortes e contrastantes, com figuras triangulares e linhas inclinadas antepostas a padrões verticais, ampliando ainda mais o sentido de conflito e desequilíbrio na cena. Imagens refletidas em imagens, numa fantasmagoria de reflexos, passam o sentido de barulho caótico e a superficialidade da vida moderna, como se tivéssemos perdido o controle sobre os frutos do progresso.

O espaço de tranqüilidade e serenidade presente no lar do primeiro quadro materializou-se numa espacialidade hipnotizante e alienante, fluida e entorpecedora. Em algum momento da história do espaço moderno o ideal virou pesadelo.

É interessante que muitos críticos de arte sugerem estar a mulher do quadro de Vermeer recebendo uma carta de seu amante ou do marido, que desconhece o fato da gravidez, que gerará provavelmente um filho do amante; daí o ar de preocupação da mulher. Caso optemos por essa perspectiva, com certeza o sentido profético do quadro realiza-se na paisagem de Eddy. A corrupção, a mentira e a ilusão estavam presentes desde a origem, na idéia de progresso como constituidor da espacialidade do mundo burguês. 


\section{Para terminar}

Estas representações conflituosas refletem a complexidade da relação homem-mundo que, permeada pela relação homem-homem, gera uma sociedade espacializada na lógica das contradiçōes dessas relaçōes, estabelecendo sua unidade na e pela diversidade. A paisagem que se olha — quando se olha - é fruto de várias mudanças de referenciais e características específicas a cada tempo e lugar, mas a atualidade dessa paisagem delineia-se pela velocidade e pela fragmentação dos elementos que a compõem; perde-se aí o sentido dos detalhes por não conseguir entender a noção de conjunto, fazendo da vertigem a sensação mais usual àquelas individualidades ou coletividades que olham $\mathrm{e}$ tentam interpretar o mundo.

Por mais conflituosas que sejam as representações das obras aqui apresentadas, temos condiçôes de entender esta diversidade a partir dos objetivos, do contexto histórico-social e dos limites perceptivos dos seus autores. Estes expressam a tentativa do homem de realizar um componente central à sua humanidade: a busca de compreensão do mundo, ou seja, de sentido às suas perguntas e às respostas possíveis.

Vamos, assim, finalizando esta rápida e genérica leitura geográfica da pintura, a partir dos nossos interesses pela expressão de dada espacialidade por meio das obras. Como vimos no início deste artigo, a linguagem pictórica possui alguns elementos que a definem e contribuem para o entendimento e a interpretação das obras. Contudo, não é aplicando uma cartilha com suas regras que se poderá usufruir de toda a riqueza presente em cada quadro; esses elementos servem apenas de parâmetros para análises mais objetivas. O desafio é buscar mais elementos que enriqueçam de informação o contexto em que certa pintura foi elaborada e, a partir disso, poder estabelecer relaçóes com o complexo espacial que estamos vivenciando.

Cada pintura aqui trabalhada, mesmo não tendo por prioridade temática a representação espacial da sociedade em que o pintor vivia, acaba passando informaçōes sobre esta por meio dos elementos técnicos e tecnológicos que ele empregou e pela forma de abordagem dos temas, além, é claro, das próprias imagens elaboradas.

Retornando à questão do olhar e do geógrafo, vemos que os quadros aqui apresentados foram frutos de uma dada forma de olhar o mundo. Cada pintor tenta expressar os seus questionamentos e as interpretaçôes que faz, por meio dos recursos, das restriçôes e das possibilidades que possui. Os condicionantes técnicos e tecnológicos logicamente influenciam na definição do estilo, mas as formas que este toma sugerem uma tentativa de ir além dos limites perceptivos, apesar de estar sob influência destes. 
Aprender a ver pinturas pode auxiliar numa melhor leitura do espaço, assim como uma análise geográfica dos quadros pode enriquecer a compreensão deles. E isso o geógrafo, pesquisador e/ou professor, precisa exercitar por excelência.

\section{Referências bibliográficas}

ARGAN, Giulio. Arte moderna. São Paulo: Companhia das Letras, 1992. 709 p.

BECKETT, Wendy. História da pintura. Portugal: Livros e Livros, 1994. 400 p.

CUMMING, Robert. Para entender a Arte. São Paulo: Ática, 1996. 104 p.

DONDIS, D. A. Sintaxe da linguagem visual. São Paulo: Martins Fontes, 1997. 236 p.

ELIOT, T. S. Poesia. Rio de Janeiro: Nova Fronteira, 1981. 313 p.

FERRAZ, Cláudio B. Geografia e paisagem - entre o olhar e o pensar. 2002. 380 p. Tese (Doutorado em Geografia) — FFLCH/USP, SP.

MOREIRA, Ruy. O discurso do avesso. Rio de Janeiro: Dois Pontos, 1987. 180 p.

OSTROWER, Fayga. A construção do olhar. In: NOVAIS, Adauto (Org.). O olhar. São Paulo: Companhia das Letras, 1988. p. 167-182.

TÁPIES, Antonio. A prática da arte. In: História geral da Arte. Rio de Janeiro: Ediciones Del Prado, 1995. p. 7-8. v. 1.

THARRATS, Joan-Josep. Apresentação. História geral da Arte. Rio de Janeiro: Ediciones Del Prado, 1995. p. 9-17. v. 1.

Recebido em 31 de outubro de 2008 e aprovado em 06 de março de 2009. 